\title{
openheart Early versus newer generation devices for transcatheter aortic valve implantation in routine clinical practice: a propensity score matched analysis
}

\author{
Thomas Pilgrim, ${ }^{1}$ Joe K T Lee, ${ }^{1}$ Crochan J O'Sullivan, ${ }^{2}$ Stefan Stortecky, ${ }^{1}$ \\ Sara Ariotti, ${ }^{1}$ Anna Franzone, ${ }^{1}$ Jonas Lanz, ${ }^{1}$ Dik Heg, ${ }^{3}$ Masahiko Asami, \\ Fabien Praz, ${ }^{1}$ George C M Siontis, ${ }^{1}$ René Vollenbroich, ${ }^{1}$ Lorenz Räber, ${ }^{1}$ \\ Marco Valgimigli, ${ }^{1}$ Eva Roost, ${ }^{4}$ Stephan Windecker ${ }^{1}$
}

To cite: Pilgrim T, Lee JKT, 0'Sullivan CJ, et al. Early versus newer generation devices for transcatheter aortic valve implantation in routine clinical practice: a propensity score matched analysis. Open Heart 2018;5:e000695. doi:10.1136/ openhrt-2017-000695

Received 8 August 2017 Revised 16 November 2017 Accepted 20 November 2017

\section{Check for updates}

${ }^{1}$ Department of Cardiology, University of Bern, Bern, Switzerland

${ }^{2}$ Triemlispital, Zurich, Switzerland

${ }^{3}$ Clinical Trials Unit, University of Bern, Bern, Switzerland ${ }^{4}$ Department of Cardiovascular Surgery, University of Bern, Bern, Switzerland

Correspondence to Dr Thomas Pilgrim; thomas. pilgrim@insel.ch

\section{ABSTRACT}

Aim Contemporary data comparing early versus newer generation transcatheter heart valve (THV) devices in routine clinical practice are lacking. We sought to compare the safety and efficacy of early versus newer generation THVs in unselected patients undergoing transcatheter aortic valve implantation (TAVI).

Methods and results We performed a propensity score matched analysis of patients undergoing transfemoral TAVI at a single centre with early versus newer generation devices between 2007 and 2016. Patients were matched for balloon-expandable versus self-expandable valves and Society of Thoracic Surgeons score. The primary end point was the Valve Academic Research Consortium (VARC)-2 early safety composite end point at 30 days. Among the 391 matched pairs, no differences between early $(21.2 \%)$ and newer generation (20.8\%) THVs regarding the early safety composite end point (HR $0.98,95 \% \mathrm{Cl} 0.72$ to 1.33 , $\mathrm{P}=0.88$ ) were observed. The rates of valve embolisation ( $0.8 \%$ vs $4.2 \%, P=0.005)$, bleeding events $(24.8 \%$ vs $32.0 \%, \mathrm{P}=0.028$ ) and moderate-to-severe paravalvular regurgitation (PVR) $(3.1 \%$ vs $12.1 \%, \mathrm{P}<0.001)$ were lower among patients receiving newer generation devices. Conversely, patients treated with early generation THVs less frequently experienced annulus rupture ( $0 \%$ vs $2.0 \%$, $\mathrm{P}=0.008$ ).

Conclusion Newer compared with early generation THV devices were associated with a lower rate of valve embolisation, PVR and bleeding events.

\section{INTRODUCTION}

Transcatheter aortic valve implantation (TAVI) has rapidly evolved as a treatment strategy for inoperable patients with severe aortic stenosis (AS) and as a viable therapeutic alternative to surgical aortic valve replacement (SAVR) among high-risk and intermediate-risk patients. TAVI using the first-generation balloon-expandable (Edwards SAPIEN and SAPIEN XT, Edwards Lifesciences, Irvine, California, USA) transcatheter heart valve (THV) device was shown to

\section{Key questions}

What is already known about this subject?

- First-generation transcatheter heart valve (THV) devices are associated with issues including paravalvular aortic regurgitation, vascular complications, strokes and conduction disturbances, which are associated with worse prognosis.

- Data on newer generation THVs are mainly derived from registries focusing on one particular valve type and unselected data on all-comer patients receiving any newer generation THV are lacking.

What does this study add?

- This study provides evidence that the newer generation THVs are as safe as the early generation devices regarding the comparable Valve Academic Research Consortium-2 early safety composite end points.

- The specific designs of the newer generation THVs are of benefit to reduce THV migration, bleeding complications and paravalvular regurgitation.

How might this impact on clinical practice?

- A tailored use of THV devices based on patient anatomical and prosthesis characteristics may exploit the full potential of these new devices.

be superior to the guideline-directed medical therapy and non-inferior to SAVR at $1^{1}$ and 5 years follow-up. ${ }^{2}$ In addition, TAVI using the self-expandable CoreValve (Medtronic, Minneapolis, Minnesota, USA) was observed to be superior to SAVR at 3-year follow-up. ${ }^{3}$

However, first-generation THV devices are associated with issues including paravalvular aortic regurgitation (PVR), vascular complications, strokes and conduction disturbances. In particular, moderate-to-severe PVR is significantly higher following TAVI with early generation THV devices as compared with 
SAVR and is associated with impaired prognosis during medium-term to long-term follow-up. ${ }^{45}$ Subsequent iterations of early generation self-expandable and balloon-expandable devices feature smaller delivery sheaths, more controllable deployment mechanisms and circumferential cuffs and skirts to address the aforementioned limitations of first-generation THV devices. ${ }^{6}$ Hitherto, data on newer generation THVs are mainly derived from registries focusing on one particular valve type and unselected data on all-comer patients receiving any newer generation THV are lacking. ${ }^{7-9}$

Therefore, the objective of our study was to compare 30 day safety and efficacy of early and newer generation THV devices in a prospective real world registry of consecutive patients.

\section{METHODS}

\section{Study population}

All patients undergoing TAVI at Bern University Hospital are consecutively enrolled in a prospective registry. For the purpose of the present analysis, we investigated all patients treated by transfemoral access and excluded patients with alternative access. The selection of patients with severe AS eligible for TAVI, device allocation and periprocedural management was left to the discretion of the operators. The antiplatelet and antithrombotic regimen has not been modified throughout the entire period of inclusion and consisted of dual antiplatelet therapy for 6 months in patients with no indication for oral anticoagulation. One antiplatelet agent was added in patients with indication of oral anticoagulation and recent stent implantation, and oral anticoagulation alone was prescribed in all other patients. All data were recorded in a web-based database held at the Clinical Trial Unit at the University of Bern, Switzerland. The Bern TAVI registry has been approved by the local cantonal Ethics Committee. All patients provided written informed consent to participate to this registry.

\section{Devices}

All TAVI devices used for transfemoral access were dichotomised into early and newer generation devices. Medtronic CoreValve, Edwards SAPIEN THV and Edwards SAPIEN XT were considered early generation devices, whereas Edwards SAPIEN 3 (Edwards Lifesciences), LOTUS valve system (Boston Scientific, Natwick, Massachusetts, USA) and Medtronic Evolut R (Medtronic) were considered newer generation devices. All these newer generation THV devices are available since 2014 for commercial use and implantation in Switzerland.

\section{Definitions and follow-up}

After discharge following the index hospitalisation, patients were contacted the first time for a 30-day clinical follow-up. Standardised interviews, documentation from referring physicians and hospital discharge summaries were used for the collection of clinical end points. All safety and efficacy end points were defined according to the updated version of the Valve Academic Research Consortium (VARC-2) definition. ${ }^{10}$ All adverse events were adjudicated by an independent Clinical Events Committee. The primary prespecified end point of our analysis was the VARC-2 early safety outcome, a composite of all-cause death, stroke, life-threatening bleeding, acute kidney injury stage 2 or 3 , coronary obstruction requiring intervention, major vascular complications and valve-related dysfunction requiring repeat procedure.

\section{Statistical analysis}

Patients were matched on Society of Thoracic Surgeons (STS) predicted risk of mortality score within the non-self-expandable devices (generating Edwards SAPIEN THV/XT vs SAPIEN 3 matched pairs, $n=190$ pairs) and separately on STS score within the self-expandable devices (generating Medtronic CoreValve vs Evolut R or Boston Scientific LOTUS matched pairs, $\mathrm{n}=201$ pairsincluding $\mathrm{n}=105$ Evolut $\mathrm{R}$ and $\mathrm{n}=96$ LOTUS). Continuous data are reported as mean $\pm \mathrm{SD}$ and compared using the Student's t-test. Categorical variables are reported as counts and percentages and were compared using the $\mathrm{X}^{2}$ or Fisher's exact test, as appropriate. Event rates at 30 days were compared for patients who underwent newer versus early generation THV devices implantation using Cox's regression, censoring patients at death or lost to follow-up. Reported are crude HRs with $95 \%$ CIs, with $P$ values from Wald $X^{2}$ tests comparing newer versus early generation THV devices, or continuity correct risk ratio with $\mathrm{P}$ values from Fisher's exact tests in case of zero events, throughout. Landmark analyses were performed using a landmark set at 3 days since the TAVI procedure. HRs per period (0-3 days, or 4-30 days) were again calculated using Cox's regressions for each period separately, and whether these HRs differed per period were tested using an interaction test (THV generation $\mathrm{x}$ period) with robust SEs. Stratified analysis of the following subgroups were performed: age ( $\geq 80$ years vs $<80$ years), gender (female vs male), diabetes (diabetic vs non-diabetic), atrial fibrillation (yes vs no), left ventricular ejection fraction ( $\leq 30 \%$ vs $>30 \%, n=89$ patients with missing data), renal failure with an estimated glomerular filtration rate $<30 \mathrm{~mL} / \mathrm{min}$ (yes vs no, $\mathrm{n}=3$ patients with missing data), peripheral artery disease (yes vs no) and additionally the $\mathrm{P}$ value for interaction between subgroups and device generation is reported.

For all analyses, a two-sided $\alpha<0.05$ was considered to be statistically significant. All statistical analyses were performed using the Stata software, V.14.2 (StataCorp, College Station, Texas, USA).

\section{RESULTS}

\section{Patient population}

Among 1232 patients undergoing TAVI at Bern University Hospital between 14 August 2007 and 30 June 2016, we derived 391 propensity score matched pairs (figure 1). 


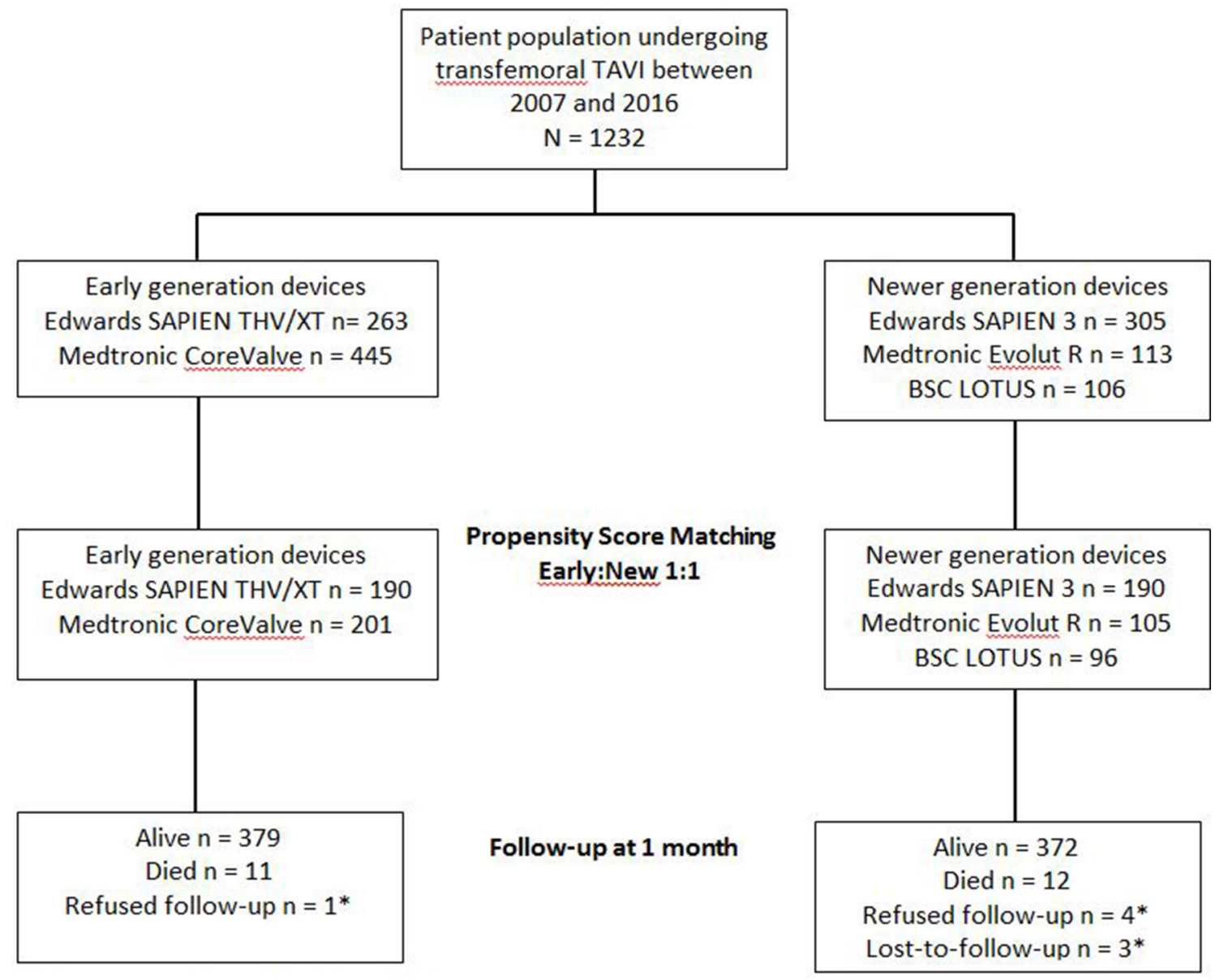

Figure 1 Flow diagram of patients included into the propensity score matched analysis. *Patient censored at last scheduled or unscheduled contact. BSC, Boston Scientific; TAVI, transcatheter aortic valve implantation; THV, transcatheter heart valve.

Baseline characteristics were well balanced between the two groups (table 1 ).

As compared with patients treated with the newer generation THV devices, those treated with the early generation THV had a higher prevalence of renal failure (38.3\% vs $24,7 \%, \mathrm{P}<0.001)$, and a lower prevalence of carotid artery disease $(5.5 \%$ vs $10.6 \%, \mathrm{P}=0.017)$.

\section{Procedural characteristics}

Procedural characteristics are summarised in table 2.

Procedure time was significantly shorter $(63.2 \pm 27.8$ vs $68.8 \pm 34.2 \mathrm{~min}, \mathrm{P}=0.014)$ and contrast volume significantly lower $(161 \pm 57$ vs $234 \pm 99 \mathrm{~mL} ; \mathrm{P}<0.001)$ in patients treated with newer as compared with earlier generation THV devices, respectively. Patients treated with newer generation devices less frequently underwent predilatation $(58.8 \%$ vs $88.5 \%, \mathrm{P}<0.001)$. The rate of valve migration or embolisation was significantly lower among patients receiving newer as compared with an early generation devices $(0.8 \%$ vs $4.0 \%, \mathrm{P}<0.001)$. Conversely, patients treated with early generation devices less frequently experienced annulus rupture and/or aortic dissection $(0 \%$ vs $2.0 \%, \mathrm{P}=0.008)$. Patients treated with newer generation THV devices had a lower rate of moderate or severe PVR $(3.1 \%)$ as compared with patients treated with early generation devices $(12.1 \%)(\mathrm{P}<0.001)$.

\section{Thirty-day clinical outcomes}

Clinical follow-up at 30 days was complete in all patients. The VARC-2 early safety composite end point was observed in $20.8 \%$ of patients treated with newer generation THV devices and in $21.2 \%$ of patients treated with early generation THV devices (HR $0.98,95 \%$ CI 0.72 to 1.33, $\mathrm{P}=0.876$ ) (figure 2). A landmark analysis set at 3 days showed no differences in timing of events between the two groups in the early or late phase after TAVI, respectively (figure 3 ). The individual components of the primary composite end point are reported in table 3 .

There were no significant differences between patients treated with early versus newer generation THV devices with regard to all-cause mortality $(4.9 \%$ vs $3.9 \%$, HR $0.80,95 \% \mathrm{CI} 0.41$ to $1.58, \mathrm{P}=0.519)$ and stroke $(4.1 \%$ vs $3.9 \%$, HR $0.94,95 \%$ CI 0.47 to 1.91 , $\mathrm{P}=0.868$ ). Bleeding events were more common among patients treated with early as compared with newer generation devices $(32.0 \%$ vs $24.8 \%$, HR $0.74,95 \%$ CI 0.57 to $0.97, \mathrm{P}=0.028$ ), whereas the rates of vascular access site complications were comparable (major or minor, $24.8 \%$ vs $23.9 \%$, HR 0.96 , $95 \%$ CI 0.72 to 1.27 , $\mathrm{P}=0.757$ ). In a stratified analysis for the VARC-2 early safety outcome, there were no significant interactions across major subgroups (figure 4 ). 
Table 1 Baseline characteristics

\begin{tabular}{|c|c|c|c|}
\hline & \multirow{2}{*}{$\begin{array}{l}\text { Early generation TAVI } \\
\text { devices } \\
\mathrm{n}=391\end{array}$} & \multirow{2}{*}{$\begin{array}{l}\text { Newer generation TAVI } \\
\text { devices } \\
\mathrm{n}=391\end{array}$} & \multirow[b]{2}{*}{$P$ value } \\
\hline & & & \\
\hline Age (years) & $82.29 \pm 5.67$ & $82.67 \pm 6.35$ & 0.377 \\
\hline Female gender, $\mathrm{n}(\%)$ & $207(52.9)$ & $208(53.2)$ & 1.000 \\
\hline Body mass index $\left(\mathrm{kg} / \mathrm{m}^{2}\right)$ & $26.26 \pm 4.94$ & $26.45 \pm 5.23$ & 0.614 \\
\hline \multicolumn{4}{|l|}{ Risk assessment } \\
\hline STS score & $5.04 \pm 2.83$ & $5.09 \pm 2.80$ & 0.792 \\
\hline Logistic EuroSCORE & $18.02 \pm 11.15$ & $18.08 \pm 13.23$ & 0.945 \\
\hline \multicolumn{4}{|l|}{ Cardiac risk factors } \\
\hline Diabetes mellitus, $\mathrm{n}(\%)$ & $82(21.0)$ & $108(27.6)$ & 0.037 \\
\hline Hypertension, n (\%) & $323(82.6)$ & $327(83.6)$ & 0.775 \\
\hline Dyslipidemia, n (\%) & $233(59.6)$ & $255(65.2)$ & 0.121 \\
\hline \multicolumn{4}{|l|}{ Clinical features } \\
\hline Renal failure (GFR <60 mL/min/1.73 m²) & $149(38.3 \%)$ & $96(24.7 \%)$ & $<0.001$ \\
\hline COPD, n (\%) & $46(11.8)$ & $35(9.0)$ & 0.240 \\
\hline Atrial fibrillation, n (\%) & $134(34.3)$ & $138(35.3)$ & 0.822 \\
\hline Permanent pacemaker, n (\%) & $40(10.2)$ & $43(11.0)$ & 0.817 \\
\hline \multicolumn{4}{|l|}{ Past medical history } \\
\hline Previous stroke or TIA, n (\%) & $34(8.7)$ & $44(11.3)$ & 0.283 \\
\hline Carotid artery disease, n (\%) & $21(5.5)$ & $29(10.6)$ & 0.017 \\
\hline Coronary artery disease, $\mathrm{n}(\%)$ & $231(59.1)$ & $249(63.7)$ & 0.212 \\
\hline Previous myocardial infarction, $\mathrm{n}(\%)$ & $52(13.3)$ & $55(14.1)$ & 0.835 \\
\hline Previous intervention, $\mathrm{n}(\%)$ & $108(27.6 \%)$ & $134(34.3 \%)$ & 0.053 \\
\hline $\mathrm{CABG}$ & $32(8.5 \%)$ & $41(10.5 \%)$ & 0.390 \\
\hline $\mathrm{PCl}$ & $86(22.0 \%)$ & $106(27.2 \%)$ & 0.097 \\
\hline Peripheral vascular disease, $\mathrm{n}(\%)$ & $39(10.0 \%)$ & $24(6.1 \%)$ & 0.065 \\
\hline \multicolumn{4}{|l|}{ Echocardiographic findings } \\
\hline Mean aortic valve area $\left(\mathrm{cm}^{2}\right)$ & $0.65 \pm 0.23$ & $0.68 \pm 0.27$ & 0.106 \\
\hline Mean aortic valve gradient (mm Hg) & $43.19 \pm 16.48$ & $41.45 \pm 19.07$ & 0.199 \\
\hline $\operatorname{LVEF}(\%)$ & $55.50 \pm 14.21$ & $54.18 \pm 15.50$ & 0.239 \\
\hline Moderate/severe mitral regurgitation & $68(18.9 \%)$ & $58(15.6 \%)$ & 0.242 \\
\hline
\end{tabular}

CABG, coronary artery bypass grafting; COPD, chronic obstructive pulmonary disease; GFR, glomerular filtration rate; LVEF, left ventricular ejection fraction; PCl, percutaneous coronary intervention; STS, Society of Thoracic Surgeons; TAVI, transcatheter aortic valve implantation; TIA, transient ischaemic attack.

\section{DISCUSSION}

We present a propensity score matched comparison of clinical outcomes among unselected patients treated with early versus newer generation THV devices in routine clinical practice. The main findings of the present analysis can be summarised as follows: (1) there was no significant difference in the risk of the 30-day VARC-2 safety composite end point between early and newer generation THV devices; (2) newer generation devices decreased the risk of valve migration or embolisation; (3) moderate or severe PVR occurred less frequently with newer as compared with earlier generation THV devices; (4) there was a decreased risk of bleeding among patients treated with newer generation devices.
There were no significant differences in the composite early safety outcome between patients treated with early as compared with newer generation THV devices. Recently, it has been reported that the most important causes of 30-day mortality after TAVI are heart failure and cardiac arrest (40.3\% of deaths) followed by vascular and bleeding complications (16.8\% of deaths), stroke ( $10.9 \%$ of deaths), sepsis ( $10.9 \%$ of deaths) and cardiac tamponade (10.1\% of deaths). ${ }^{11}$ Moreover, acute kidney injury stage $\geq 2$, preprocedural hospitalisation for heart failure, periprocedural acute myocardial infarction and increased probrain natriuretic peptide have been identified as independent predictors of 30-day mortality. ${ }^{12}$ Our analysis revealed no significant differences between 
Aortic and vascular disease

Table 2 Procedural characteristics

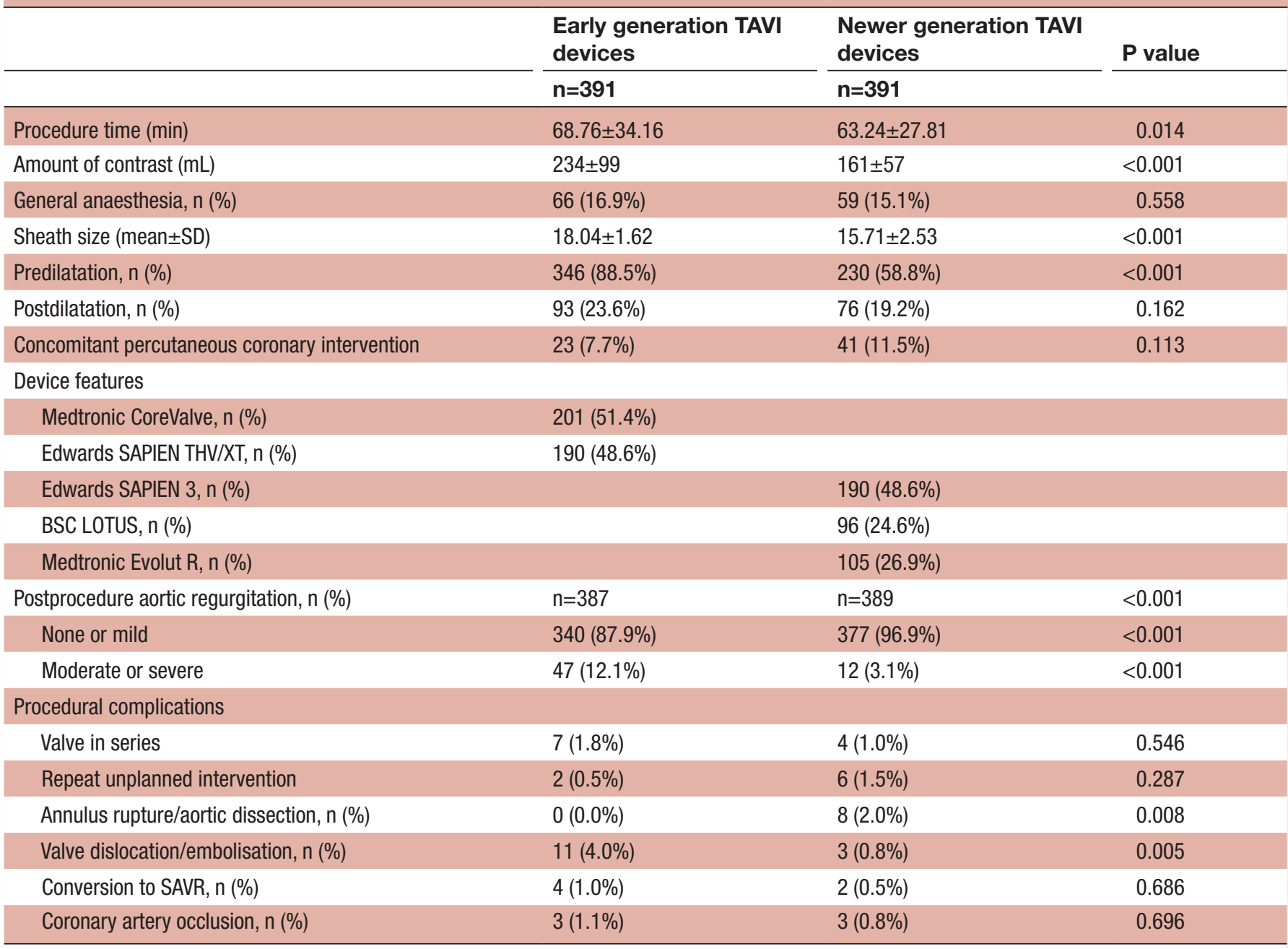

BSC, Boston Scientific; SAVR, surgical aortic valve replacement; TAVI, transcatheter aortic valve implantation; THV, transcatheter heart valve.

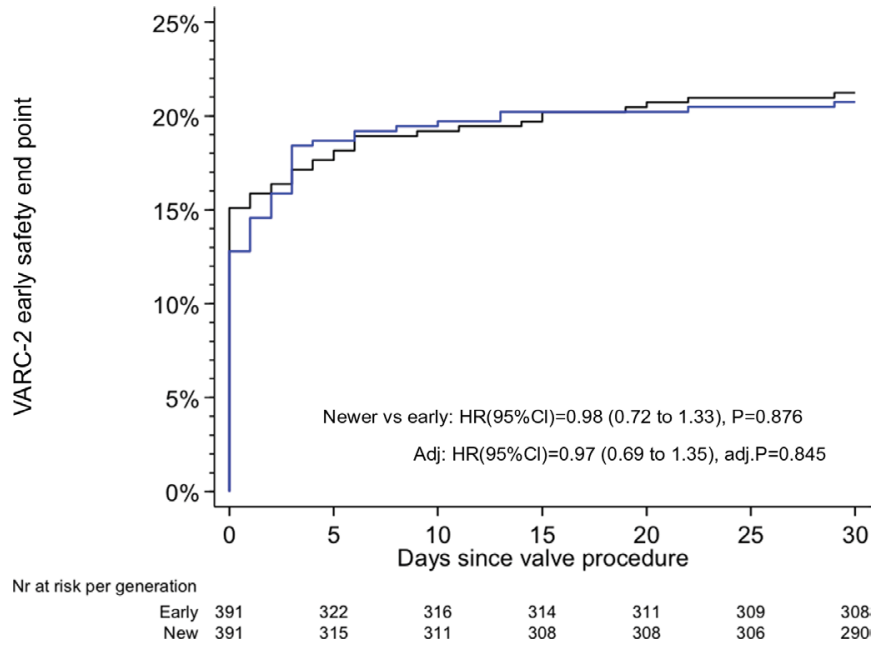

Figure 2 Kaplan-Meier estimates of the VARC-2 early composite safety outcome. The blue line relates to the newer generation TAVI devices; the black line relates to the early generation TAVI devices. TAVI, transcatheter aortic valve implantation; VARC, Valve Academic Research Consortium.

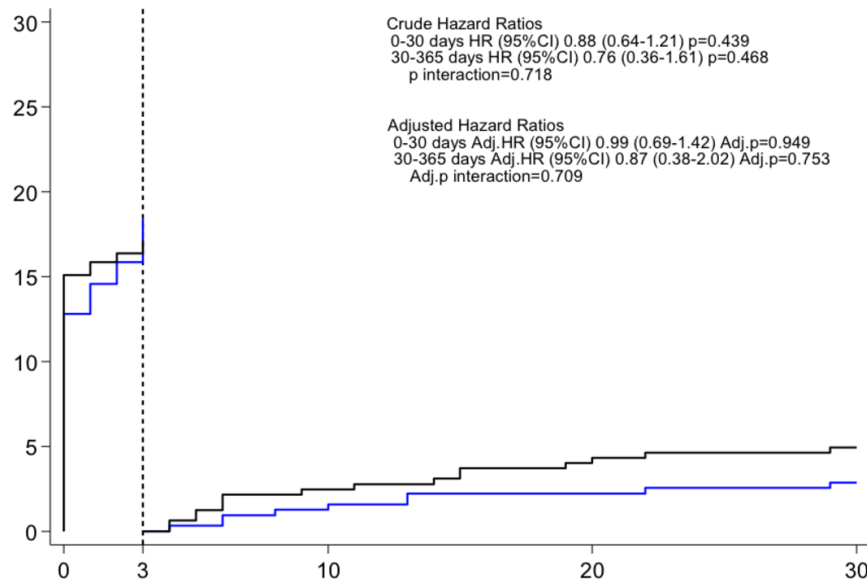

Figure 3 Kaplan-Meier estimates of the VARC-2 early composite safety outcome landmark analysis between 0 and 3 days and 4 and 30 days. The blue line relates to the newer generation TAVI devices; the black line relates to the early generation TAVI devices. TAVI, transcatheter aortic valve implantation; VARC, Valve Academic Research Consortium. 
Table 3 Adjudicated clinical outcomes at 30 days follow-up

\begin{tabular}{|c|c|c|c|c|}
\hline & \multirow{3}{*}{$\begin{array}{l}\text { Early generation TAVI } \\
\text { devices }\end{array}$} & \multirow{3}{*}{$\begin{array}{l}\begin{array}{l}\text { Newer generation } \\
\text { TAVI devices }\end{array} \\
\mathrm{n}=391 \\
\end{array}$} & \multirow{2}{*}{\multicolumn{2}{|c|}{$\begin{array}{l}\text { Newer generation vs early } \\
\text { generation } \\
\text { Crude }\end{array}$}} \\
\hline & & & & \\
\hline & & & HR $(95 \%$ Cl) & $P$ value \\
\hline \multicolumn{5}{|l|}{ 30-day follow-up } \\
\hline Early safety composite end point, $n(\%)$ & $83(21.2)$ & $81(20.8)$ & 0.98 (0.72 to 1.33$)$ & 0.876 \\
\hline All-cause death, $n(\%)$ & $19(4.9)$ & $15(3.9)$ & 0.80 (0.41 to 1.58$)$ & 0.519 \\
\hline Cardiovascular death, $\mathrm{n}(\%)$ & $18(4.6)$ & $11(2.8)$ & $0.62(0.29$ to 1.31$)$ & 0.210 \\
\hline CVE, n (\%) & $17(4.4)$ & $17(4.4)$ & 1.00 (0.51 to 1.97$)$ & 0.989 \\
\hline Stroke & $16(4.1)$ & $15(3.9)$ & 0.94 (0.47 to 1.91$)$ & 0.868 \\
\hline Disabling stroke & $14(3.6)$ & $9(2.3)$ & 0.64 (0.28 to 1.49$)$ & 0.301 \\
\hline Non-disabling stroke & $2(0.5)$ & $6(1.6)$ & 3.05 (0.61 to 15.09$)$ & 0.172 \\
\hline Transient ischaemic attack & $1(0.3)$ & $2(0.5)$ & $2.02(0.18$ to 22.25$)$ & 0.567 \\
\hline Myocardial infarction, $n(\%)$ & $2(0.5)$ & $2(0.5)$ & $1.00(0.14$ to 7.10$)$ & 1.000 \\
\hline All-cause death or CVE, $n(\%)$ & $26(6.7)$ & $29(7.5)$ & 1.13 (0.66 to 1.91$)$ & 0.661 \\
\hline Cardiovascular death or CVE, n (\%) & $25(6.4)$ & $26(6.7)$ & 1.05 (0.61 to 1.81$)$ & 0.867 \\
\hline Bleeding events, n (\%) & $125(32.0)$ & $96(24.8)$ & 0.74 (0.57 to 0.97$)$ & 0.028 \\
\hline Life-threatening or disabling bleeding & $33(8.5)$ & $18(4.6)$ & $0.54(0.30$ to 0.96$)$ & 0.036 \\
\hline Major bleeding & $71(18.2)$ & $42(10.8)$ & 0.58 (0.39 to 0.85$)$ & 0.005 \\
\hline Minor bleeding & $27(7.0)$ & $39(10.1)$ & 1.46 (0.90 to 2.39$)$ & 0.128 \\
\hline $\begin{array}{l}\text { Vascular access site and access-related } \\
\text { complications, } \mathrm{n}(\%)\end{array}$ & $97(24.8)$ & $93(23.9)$ & 0.96 (0.72 to 1.27$)$ & 0.757 \\
\hline Major vascular complications & $42(10.7)$ & $47(12.1)$ & $1.12(0.74$ to 1.70$)$ & 0.587 \\
\hline Minor vascular complications & $55(14.1)$ & $44(11.3)$ & 0.80 (0.54 to 1.18$)$ & 0.260 \\
\hline Permanent pacemaker implantation & $84(21.7)$ & $89(23.2)$ & $1.08(0.80$ to 1.45$)$ & 0.617 \\
\hline Acute kidney injury, $\mathrm{n}(\%)$ & $27(6.9)$ & $17(4.4)$ & $0.63(0.34$ to 1.16$)$ & 0.138 \\
\hline Stage 1, n (\%) & $18(4.6)$ & $2(0.5)$ & 0.11 (0.03 to 0.48$)$ & 0.003 \\
\hline Stage 2, n (\%) & $0(0.0)$ & $5(1.3)$ & 11.00 (0.61 to 198.26$)$ & 0.062 \\
\hline Stage 3, n (\%) & $9(2.3)$ & $10(2.6)$ & 1.12 (0.46 to 2.76$)$ & 0.800 \\
\hline
\end{tabular}

CVE, cerebrovascular event; TAVI, transcatheter aortic valve implantation.

\begin{tabular}{|c|c|c|c|c|c|}
\hline & \multicolumn{2}{|c|}{$\begin{array}{l}\text { Early generation New generation } \\
\text { TAVI devices TAVI devices }\end{array}$} & \multicolumn{2}{|c|}{ New generation vs Early generation } & \multirow[b]{2}{*}{$\begin{array}{l}\text { interaction } \\
\text { p-value }\end{array}$} \\
\hline & $N=391$. & $N=391$ & 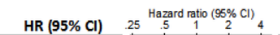 & $p$-value & \\
\hline Age & & & & & \\
\hline$\geq 80$ years & 63/282 & $55 / 298$ & $0.82(0.57-1.17)$ & & \\
\hline $\begin{array}{l}<80 \text { years } \\
\text { Gender }\end{array}$ & 20/109 & 26/93 & $1.57(0.87-2.281)$ & 0.132 & 0.844 \\
\hline female & 48/207 & $46 / 208$ & $0.95(0.63-1.42)$ & 0.794 & \\
\hline male & 35/184 & 35/183 & $1.01(0.63-1.62)$ & 0.964 & \\
\hline $\begin{array}{l}\text { Diabbets } \\
\text { diabetics }\end{array}$ & $20 / 82$ & 23/108 & $0.87(0$. & 33 & 0.691 \\
\hline $\begin{array}{l}\text { non-diabetics } \\
\text { Atrial fibrillation }\end{array}$ & 63/309 & 58/283 & $1.00(0.70-1.44)$ & 0.979 & 0.521 \\
\hline yes & 27/134 & $31 / 138$ & $1.12(0.67-1.87)$ & 0.6 & \\
\hline & $56 / 257$ & 50/253 & $0.91(0.62-1.33)$ & 0.614 & ביבר \\
\hline$<<0 \%$ & & & $1.15(0.49-2.69)$ & 18 & \\
\hline $230 \%$ & $65 / 322$ & $58 / 299$ & $0.96(0.67-1.37)$ & 0.821 & \\
\hline Renal failure $\mathrm{C}$ & nl/min eGFR) & & & & 0.805 \\
\hline yes & $11 / 38$ & $16 / 62$ & $0.88(0.41-1.90)$ & 0.753 & \\
\hline $\begin{array}{l}\text { no } \\
\text { Peripheral artery }\end{array}$ & $\begin{array}{l}\quad 71 / 351 \\
\text { lisease }\end{array}$ & 65/327 & $0.98(0.70-1.38)$ & 0.918 & 0.144 \\
\hline yes & $9 / 39$ & $10 / 24$ & $1.92(0.78-4.74)$ & 0.155 & \\
\hline no & $74 / 352$ & 71/367 & $\begin{array}{l}0.92(0.66-1.27) \\
\text { tavours new }\end{array}$ & $\begin{array}{l}0.607 \\
\text { tion }\end{array}$ & \\
\hline
\end{tabular}

Figure 4 Stratified analysis for the VARC-2 early composite safety outcome. eGFR, estimated glomerular filtration rate; LVEF, left ventricular ejection fraction; TAVI, transcatheter aortic valve implantation; VARC, Valve Academic Research Consortium. groups related to these factors except for a lower rate of bleeding in patients treated with newer as compared with early generation devices, and accordingly there were no differences in terms of early all-cause or cardiovascular death. Of note, also non-cardiac causes, not related to the device features, importantly contribute to all-cause mortality. ${ }^{11}$ At the same time, there were no differences in the rates of cerebrovascular events between patients treated with early as compared with newer generation devices.

We documented a lower risk of valve migration or embolisation in patients treated with newer as compared with early generation devices. This finding can be explained by the full or partial repositionability of some of the newer generation THV devices and the advent of imaging tools to facilitate precise device positioning. In turn, we noted an increased risk of aortic annulus rupture or aortic dissection in patients treated with newer as compared with early generation devices despite a similar 
proportion of balloon-expandable valves in both groups. Oversizing of balloon-expandable THVs, higher degree of calcification of the left ventricular outflow tract and balloon postdilation have been associated with rupture of the aortic root. ${ }^{13}{ }^{14}$ In addition, an oval rather than a round shape of the annulus may confer a higher risk of rupture. We did not systematically assess the degree of oversizing of the THV in relation to the annulus, and did not record the shape of the annulus, nor the extent or degree of calcification.

We found a significantly lower incidence of PVR in patients treated with newer as compared with early generation devices. Our results are consistent with the findings of a non-randomised study showing a lower risk of PVR among patients treated with Edwards SAPIEN 3 $(1.3 \%)$ compared with SAPIEN XT (5.3\%) $(\mathrm{P}=0.04) .{ }^{15}$ Low rates of PVR have also been reported in single-arm studies of patients treated with the Medtronic EVOLUT $\mathrm{R}^{16}$ and the Boston Scientific LOTUS system. ${ }^{17}$ Moderate and severe PVR have been associated with increased mortality at mid-term (>30 days),${ }^{18}$ posing an important safety concern with regard to the extension of TAVI to a lower risk patient population. Newer generation devices allow for complete or partial valve repositionability and/ or feature external sealing cuffs or internal skirts to minimise the risk of PVR. ${ }^{6}$ In addition to unique device properties, the use of three-dimensional CT for accurate measurement of the aortic annulus and modest oversizing has been shown to result in a reduction of PVR. ${ }^{19}$ Lower rates of PVR with newer generation THVs may mitigate the risk of valve degeneration and reduce valve-related mortality during extended follow-up. ${ }^{20}$

We documented a decreased risk of bleeding among patients treated with newer as compared with early generation devices; the difference was driven by life-threatening and major bleeding events. In turn, we found no difference in vascular access site complications between the two groups (table 3). Vascular access (transfemoral vs transapical), sheath diameter and closure devices have been identified as predictors of vascular access site complications. ${ }^{21-23}$ Previous studies reported vascular complications ranging from $6 \%$ to $20 \% .^{24}{ }^{25}$ The wide range of vascular complications is likely influenced by differences in applied definitions of vascular complications across various studies. Some of the newer generation devices feature a lower delivery system profile and have been shown to decrease the risk of access site complications. ${ }^{26}$ However, other newer generation devices, such as the LOTUS valve system, continue to use delivery sheath profiles comparable to early generation devices. In addition, a lower delivery sheath diameter in most newer generation devices was accompanied by an extension of transfemoral access to patients with more advanced peripheral vascular disease, which may have counterbalanced the intuitive benefit of lower profile delivery sheaths to a certain degree.

We found a similar rate of permanent pacemaker implantations (PPI) in patients treated with early versus newer generation devices. A significant difference in rates of AV conduction disturbances has been described between early generation balloon-expandable versus self-expandable devices, resulting in PPI in 5\%-12\% of patients after Edwards SAPIEN implantation versus 24\%-33\% after Medtronic CoreValve implantation. ${ }^{27}$ Recently, a trial revealed a significant increase in rates of PPI following SAPIEN 3 implantation as compared with the early generation XT $(19.1 \%$ vs $12.2 \%, \mathrm{P}=0.046) .^{28}$ Conversely, the reported rate of PPI at 30 days following newer generation Medtronic Evolut R implantation was $11.7 \%,{ }^{16}$ which is less than the 30 -day PPI rates reported after early generation Medtronic CoreValve implantation $(33.3 \%) .{ }^{27}$ Finally, rates of AV conduction disturbances were found to be relatively high after LOTUS valve implantation in both the REPRISE II study ${ }^{29}$ and the UK registry ${ }^{17}$ with PPI in $31.9 \%$ and $31.8 \%$ of patients, respectively. The impact of PPI on clinical outcomes and quality of life is a matter of ongoing debate, due to conflicting reported data in relation to 1-year mortality. ${ }^{29-31}$ Ventricular dyssynchrony caused by chronic right ventricular stimulation is one of the postulated mechanisms that adversely affect long-term prognosis among patients with a high degree of pacemaker dependency.

\section{LIMITATIONS}

First, the analysis is open to biases inherent to longitudinal comparisons. Patients were not randomised to the respective treatment group and despite propensity score matching, hidden confounders may have biased our results. Clinical outcomes result from a combination of patient characteristics, device features and procedural details such as the learning curve. While we corrected for the former two, the latter factor was not corrected for and may have biased the presented results to a certain degree. Second, the number of patients included in our analysis is limited and the follow-up does not extend beyond 30 days. Third, we did not capture data on extent and distribution of calcification in our database, which may have confounded the annular rupture rates. Fourth, we evaluated only newer generation THV devices used in our clinical practice, which represent only a portion of the CE-marked second-generation prosthesis. Therefore, our findings cannot be extended to all newer generation THV devices. And finally, early and newer generation devices within the two groups differ in particular characteristics of the device and the delivery system, and not all devices share the same newer generation features. In order to mitigate confounding by delivery mechanism, we therefore matched separately for 'self-expandable' and 'non-self-expandable' devices.

\section{CONCLUSIONS}

In a propensity score matched analysis, we observed comparable VARC-2 early safety composite outcomes in patients treated with early as compared with newer generation THV devices. Newer generation THV devices 
showed a significant reduction in terms of moderate-to-severe PVR at 30 days, and a lower rate of THV migration and bleeding complications. Further studies are required to evaluate the long-term effectiveness of newer THV devices. A tailored use of THV devices based on patient anatomical and prosthesis characteristics may exploit the full potential of these new devices.

Funding TP has received research grants to the institution from Edwards Lifesciences, Symetis, and Biotronik. SW has received research grants to the institution from Bravo, Boston Scientific and Terumo. LR has received research grants to the institution from Abbott Vascular. All other authors have nothing to disclose.

Competing interests None declared.

Patient consent Obtained.

Ethics approval Cantonal Ethics Committee of Bern.

Provenance and peer review Not commissioned; externally peer reviewed.

Open Access This is an Open Access article distributed in accordance with the Creative Commons Attribution Non Commercial (CC BY-NC 4.0) license, which permits others to distribute, remix, adapt, build upon this work non-commercially, and license their derivative works on different terms, provided the original work is properly cited and the use is non-commercial. See: http://creativecommons.org/ licenses/by-nc/4.0/

(c) Article author(s) (or their employer(s) unless otherwise stated in the text of the article) 2018. All rights reserved. No commercial use is permitted unless otherwise expressly granted.

\section{REFERENCES}

1. Smith CR, Leon MB, Mack MJ, et al. Transcatheter versus surgical aortic-valve replacement in high-risk patients. $N$ Engl J Med 2011;364:2187-98.

2. Mack MJ, Leon MB, Smith CR, et al. 5-year outcomes of transcatheter aortic valve replacement or surgical aortic valve replacement for high surgical risk patients with aortic stenosis (PARTNER 1): a randomised controlled trial. Lancet 2015;385:2477-84.

3. Deeb GM, Reardon MJ, Chetcuti S, et al. 3-Year Outcomes in HighRisk Patients Who Underwent Surgical or Transcatheter Aortic Valve Replacement. J Am Coll Cardiol 2016;67:2565-74.

4. Abdel-Wahab M, Comberg T, Büttner $\mathrm{HJ}$, et al. Aortic regurgitation after transcatheter aortic valve implantation with balloon- and self-expandable prostheses: a pooled analysis from a 2-center experience. JACC Cardiovasc Interv 2014;7:284-92.

5. Van Belle E, Juthier F, Susen S, et al. Postprocedural aortic regurgitation in balloon-expandable and self-expandable transcatheter aortic valve replacement procedures: analysis of predictors and impact on long-term mortality: insights from the FRANCE2 Registry. Circulation 2014;129:1415-27.

6. Tchetche D, Van Mieghem NM. New-generation TAVI devices: description and specifications. Eurolntervention 2014;10:U90-100.

7. Herrmann HC, Thourani VH, Kodali SK, et al. One-year clinical outcomes with SAPIEN 3 transcatheter aortic valve replacement in high-risk and inoperable patients with severe aortic stenosis. Circulation 2016;134:130-40.

8. Kodali S, Thourani VH, White J, et al. Early clinical and echocardiographic outcomes after SAPIEN 3 transcatheter aortic valve replacement in inoperable, high-risk and intermediate-risk patients with aortic stenosis. Eur Heart J 2016;37:2252-62.

9. Thourani VH, Kodali S, Makkar RR, et al. Transcatheter aortic valve replacement versus surgical valve replacement in intermediate-risk patients: a propensity score analysis. Lancet 2016;387:2218-25.

10. Kappetein AP, Head SJ, Généreux P, et al. Updated standardized endpoint definitions for transcatheter aortic valve implantation: the Valve Academic Research Consortium-2 consensus document. J Am Coll Cardiol 2012;60:1438-54.
11. Moreno R, Calvo L, Salinas P, et al. Causes of peri-operative mortality after transcatheter aortic valve implantation: a pooled analysis of 12 studies and 1223 patients. J Invasive Cardiol 2011;23:180-4.

12. Giordana F, D'Ascenzo F, Nijhoff F, et al. Meta-analysis of predictors of all-cause mortality after transcatheter aortic valve implantation. Am J Cardiol 2014;114:1447-55.

13. Blanke P, Reinöhl J, Schlensak C, et al. Prosthesis oversizing in balloon-expandable transcatheter aortic valve implantation is associated with contained rupture of the aortic root. Circ Cardiovasc Interv 2012;5:540-8.

14. Barbanti M, Yang TH, Rodès Cabau J, et al. Anatomical and procedural features associated with aortic root rupture during balloon-expandable transcatheter aortic valve replacement. Circulation 2013;128:244-53.

15. Binder RK, Stortecky S, Heg D, et al. Procedural Results and Clinical Outcomes of Transcatheter Aortic Valve Implantation in Switzerland: An Observational Cohort Study of Sapien 3 Versus Sapien XT Transcatheter Heart Valves. Circ Cardiovasc Interv 2015;8:e002653.

16. Manoharan G, Walton AS, Brecker SJ, et al. Treatment of symptomatic severe aortic stenosis with a novel resheathable supraannular self-expanding transcatheter aortic valve system. JACC Cardiovasc Interv 2015;8:1359-67.

17. Rampat R, Khawaja MZ, Byrne J, et al. Transcatheter Aortic Valve Replacement Using the Repositionable LOTUS Valve: United Kingdom Experience. JACC Cardiovasc Interv 2016;9:367-72.

18. Kodali SK, Williams MR, Smith CR, et al. Two-year outcomes after transcatheter or surgical aortic-valve replacement. N Engl J Med 2012;366:1686-95.

19. Hamm CW, Arsalan M, Mack MJ. The future of transcatheter aortic valve implantation. Eur Heart J 2016;37:803-10.

20. Pilgrim T, Windecker S. Newer-Generation Devices for Transcatheter Aortic Valve Replacement: Resolving the Limitations of FirstGeneration Valves? JACC Cardiovasc Interv 2016;9:373-5.

21. Pilgrim T, Kalesan B, Wenaweser P, et al. Predictors of clinical outcomes in patients with severe aortic stenosis undergoing TAVI: a multistate analysis. Circ Cardiovasc Interv 2012;5:856-61.

22. Barbash IM, Barbanti M, Webb J, et al. Comparison of vascular closure devices for access site closure after transfemoral aortic valve implantation. Eur Heart J 2015;36:3370-9.

23. Tamburino $\mathrm{CI}$, IMMè $\mathrm{S}$, Barbanti $\mathrm{M}$, et al. How true delivery profile diminution reduces vascular access challenges and complications. Minerva Cardioangiol 2016;64:330-8.

24. De Backer O, Arnous S, Sandholt B, et al. Safety and efficacy of using the Viabahn endoprosthesis for percutaneous treatment of vascular access complications after transfemoral aortic valve implantation. Am J Cardiol 2015;115:1123-9.

25. Gilard $M$, Eltchaninoff $H$, lung $B$, et al. Registry of transcatheter aortic-valve implantation in high-risk patients. $N$ Engl J Med 2012;366:1705-15.

26. Webb JG, Doshi D, Mack MJ, et al. A randomized evaluation of the SAPIEN XT transcatheter heart valve system in patients with aortic stenosis who are not candidates for surgery. JACC Cardiovasc Interv 2015;8:1797-806.

27. Khawaja MZ, Rajani R, Cook A, et al. Permanent pacemaker insertion after CoreValve transcatheter aortic valve implantation: incidence and contributing factors (the UK CoreValve Collaborative). Circulation 2011;123:951-60.

28. De Torres-Alba F, Kaleschke G, Diller GP, et al. Changes in the pacemaker rate after transition from edwards SAPIEN XT to SAPIEN 3 transcatheter aortic valve implantation: the critical role of valve implantation height. JACC Cardiovasc Interv 2016;9:805-13.

29. Buellesfeld L, Stortecky S, Heg D, et al. Impact of permanent pacemaker implantation on clinical outcome among patients undergoing transcatheter aortic valve implantation. J Am Coll Cardiol 2012;60:493-501.

30. Nazif TM, Dizon JM, Hahn RT, et al. Predictors and clinical outcomes of permanent pacemaker implantation after transcatheter aortic valve replacement: the PARTNER (Placement of AoRtic TraNscathetER Valves) trial and registry. JACC Cardiovasc Interv 2015;8(1 Pt A):60-9.

31. Dizon Jose' M, Nazif TM, Hess PL, et al. Chronic pacing and adverse outcomes after transcatheter aortic valve implantation. Heart 2015;101:1665-71. 